\title{
Novel oleate hydratases and potential biotechnological applications
}

\author{
Peter Leon Hagedoorn ${ }^{1}$ (D) - Frank Hollmann ${ }^{1}$ (D) - Ulf Hanefeld ${ }^{1}$ (D)
}

Received: 24 April 2021 / Revised: 19 July 2021 / Accepted: 19 July 2021 / Published online: 5 August 2021

(C) The Author(s) 2021

\begin{abstract}
Oleate hydratase catalyses the addition of water to the CC double bond of oleic acid to produce $(R)$-10-hydroxystearic acid. The enzyme requires an FAD cofactor that functions to optimise the active site structure. A wide range of unsaturated fatty acids can be hydrated at the $\mathrm{C} 10$ and in some cases the $\mathrm{C} 13$ position. The substrate scope can be expanded using 'decoy' small carboxylic acids to convert small chain alkenes to secondary alcohols, albeit at low conversion rates. Systematic protein engineering and directed evolution to widen the substrate scope and increase the conversion rate is possible, supported by new high throughput screening assays that have been developed. Multi-enzyme cascades allow the formation of a wide range of products including keto-fatty acids, secondary alcohols, secondary amines and $\alpha, \omega$-dicarboxylic acids.
\end{abstract}

\section{Key points}

- Phylogenetically distinct oleate hydratases may exhibit mechanistic differences.

- Protein engineering to improve productivity and substrate scope is possible.

- Multi-enzymatic cascades greatly widen the product portfolio.

Keywords Oleate hydratase $\cdot$ Protein engineering $\cdot 10$-hydroxystearic acid $\cdot$ Biocatalysis

\section{Introduction}

Hydratases or hydrolyases (EC 4.2.1) are enzymes that catalyse the addition of water to $\mathrm{C}=\mathrm{C}$ double bonds. The BRENDA database contains approximately 200 different enzymes that are classified as hydrolyase constituting a highly diverse collection of hydratases and dehydratases that are structurally and mechanistically distinct. There are metal-free, flavin containing, iron-sulphur cluster containing and even molybdenum/tungsten cofactor dependent enzymes. This exemplifies that nature has found very diverse paths to catalyse this basic chemical reaction. The most notable hydratases from a biochemical point of view are the TCA enzymes aconitase and fumarase. Aconitase contains a catalytic (nonredox) iron-sulphur cluster and catalyses the isomerisation of citrate to isocitrate using a dehydration and hydrations step with cis-aconitate as intermediate product. Fumarase is a

Peter Leon Hagedoorn

P.L.Hagedoorn@tudelft.nl

1 Department of Biotechnology, Delft University of Technology, Van der Maasweg 9, 2629, HZ Delft, The Netherlands non-metallo enzyme in eukaryotes, although a structurally distinct iron-sulphur cluster containing fumarase is prominent in the bacterial world. Fumarase catalyses the reversible hydration of fumarate to L-malate (Scheme 1).

Most hydratases catalyse the conversion of a narrow substrate range with high efficiency. This is consistent with their general primary metabolic functions. For biotechnological applications, however, a broader substrate acceptance would be highly desired. And although chemical trickery has been shown to expand the substrate scope for some known hydratases, a general protein engineering strategy has not been successful to date. It is therefore highly interesting to search for novel hydratases using the ever expanding genomic databases. The structural diversity makes it difficult to discover truly novel hydratases. Several promising microbial activities for novel hydratases have been described in literature. These enzymes have proven to be hard to isolate and characterise (Busch et al. 2020a).

The exception to this picture is oleate hydratase. Oleate hydratase (Ohy) catalyses the selective addition of water to the $\mathrm{C}=\mathrm{C}$ double bond in oleic acid $(\mathrm{OA})$ to produce $(R)-10$ hydroxystearic acid (10-HSA). OA is the major fatty acid in olive and rapeseed oil and is thus an abundant, renewable resource. HSA has commercial applications as a plant- 


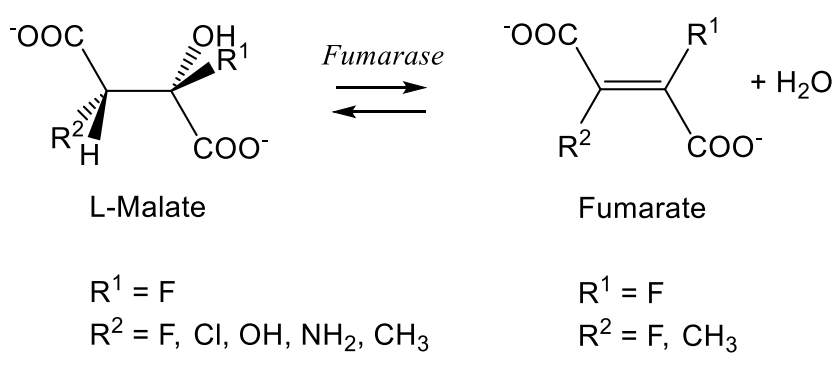

Scheme 1 The substrate scope of fumarases

derived emollient, surfactant and thickener in cosmetics and as a monomer in the polymer industry. An example is 10-HSA as an active cosmetic ingredient which is marketed by DSM as Beauactive. Ohy was already discovered as a microbial activity in the 1960s (Davis et al. 1969; Wallen et al. 1962; Schütz et al. 2019). Although one apparently successful isolation of the enzyme was undertaken in 1991, it was only many years later in 2009 that the gene encoding this enzyme was discovered in Elisabethkingia meningoseptica (Bevers et al. 2009; Hou 1995). The coding sequence was already previously annotated as a myosin-cross-reactive antigen (MCRA), which is a curious name for a microbial enzyme, as myosin is one of the major proteins of muscles in humans and animals, and the myosin superfamily proteins only occur in Eukarya. Originally MCRA was discovered as a protein from the pathogenic bacterium Streptococcus pyogenes that upon infection can lead to the generation of antibodies that also react with human heart proteins causing acute rheumatic fever (Kil et al. 1994). It was later discovered that deletion of the Ohy/MCRA coding gene in $S$. pyogenes affected the virulence of this bacterium (Volkov et al. 2010). Interestingly, it was recently found that Staphylococcus aureus Ohy protects the pathogenic bacterium against the antimicrobial unsaturated fatty palmitoleic acid on human skin (Subramanian et al. 2019). So there is an interesting human medical relevance of Ohy. The old annotation of Ohy as MCRA serves as a warning that many misleading annotations occur in existing genomic and proteomic databases, and we should always be on the lookout for such errors. The misleading annotation as myosin-cross reactive-antigen persisted for many years after its original correction and can still be found in most prominent databases to date.

As a microbial activity oleate hydratase has already been reviewed long before the discovery and characterisation of the isolated enzyme (Hou 1995). More recently, a number of (mini-)reviews on hydratases, which include segments on fatty acid hydratases and oleate hydratases, have been published (Chen et al. 2015; Demming et al. 2018; Engleder and Pichler 2018; Resch and Hanefeld 2015). Several reviews on fatty acid hydratases, including oleate hydratases, have been published in the past few years. Zhang et al. provided an excellent review on the biotechnological potential of fatty acid hydratases, including the substrate scope and possibilities of protein engineering (Zhang et al. 2020b). Löwe and Gröger published a mini-review on the applications of fatty acid hydratases in organic synthesis, highlighting the possibility to produce industrially relevant chemical building blocks from renewable resources (Löwe and Gröger 2020).

Although all these reviews offer a comprehensive overview of the published literature and important biotechnological potential of fatty acid hydratases, these articles are superseded by new recent developments as new enzymes and structures have changed our understanding of the mechanism and opened new directions for biotechnological applications. This warrants an update on the reviews that have appeared so far. Here we attempt to provide the relevant consensus on the enzyme properties, including the limitations and issues with the reported data, the current understanding of the structure and mechanism of this enzyme, and the latest developments and outlooks on biocatalysis and biotechnological applications. As a point of focus, the conversion of oleic acid to 10-HSA by the fatty acid hydratase we call oleate hydratase is central in this review. It should be noted, however, that oleate hydratases have a wider substrate scope, overlapping with other fatty acid hydratases.

\section{Oleate hydratase}

Oleate hydratase (Ohy, EC 4.2.1.53) is an FAD-containing enzyme family that has some structural and functional variations. The enzyme from a range of bacteria has been isolated and characterised (Table 1). The FAD cofactor does not have a redox function as the redox state does not change during conversion (Engleder et al. 2015; Volkov et al. 2010). The reduced cofactor $\mathrm{FADH}_{2}$ is likely the relevant species under in vivo conditions (Engleder and Pichler 2018). Ohy containing $\mathrm{FADH}_{2}$ instead of FAD was found to be circa 10 -fold more active in vitro (Engleder et al. 2015). The UV-vis properties several Ohys have been reported but the redox potentials for the cofactor have not been determined to date (Busch et al. 2020b; Engleder et al. 2015; Joo et al. 2012; Rosberg-Cody et al. 2011). The spectrum shows a somewhat unusual flavoprotein spectrum, which may reflect partially reduced cofactor (Fig. 1). Alternatively this spectrum could reflect oxidised FAD that is partially quenched due to protein binding. The current consensus is that the FAD cofactor has an essential structural role in the Ohy active site, which will be discussed in more detail below. It is not clear if and how the FAD is reduced in vivo. Fluorescence spectroscopy of Ohy under different conditions may resolve the ambiguous redox state of the FAD cofactor.

Recombinantly expressed Ohy is often partially apo, without full incorporation of the FAD cofactor, which explains why the FAD cofactor was missed in the original publication describing the isolated protein (Bevers et al. 2009). Frequently 


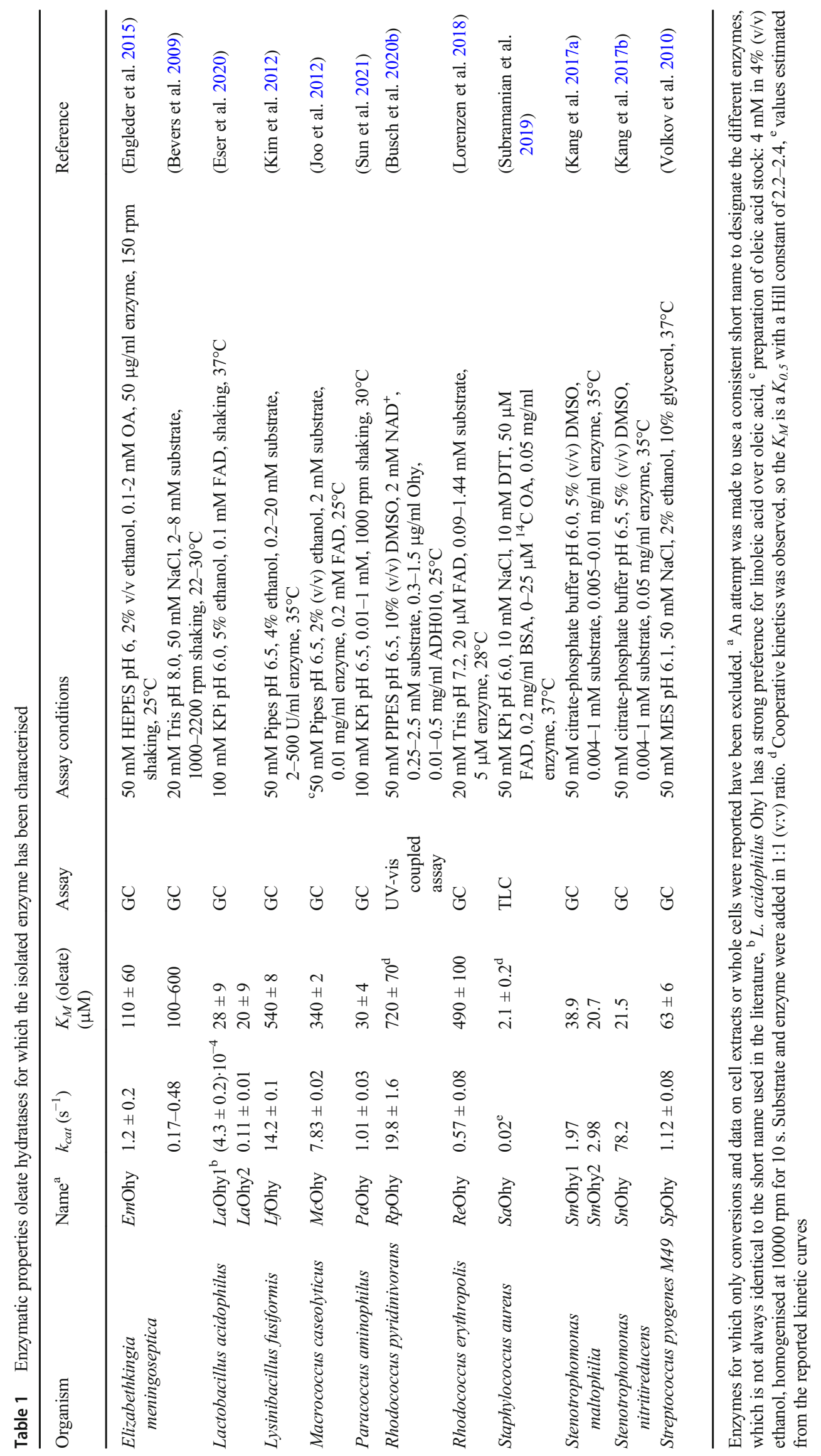




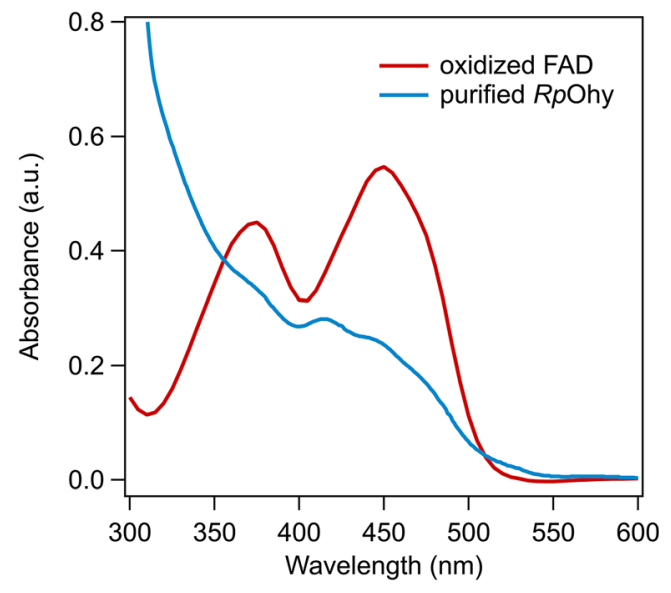

Fig. 1 UV-visible spectrum of Rhodococcus pyridinivorans Ohy (Busch et al. 2020b)

FAD is added during enzyme assays to ensure full incorporation, and crystallisation conditions of $S$. aureus SaOhy required $0.75 \mathrm{mM} F A D$ supplementation, even though the reported $K_{M}$ for supplemented FAD for optimal activity is $2.1 \mu \mathrm{M}$ (Subramanian et al. 2019). The $K_{d}$ for FAD binding to E. meningoseptica EmOhy was reported to be $1.8 \mu \mathrm{M}$ measured by isothermal titration calorimetry (ITC) (Engleder et al. 2015). This suggests that FAD is not very tightly bound, at least in the recombinantly expressed enzymes.

Although a large number of different bacterial oleate hydratases have been recombinantly produced in E. coli and the biocatalytic conversion of different fatty acids has been shown, limited enzyme kinetic data and protein characterisation have been performed to date. For example of the Ohy's from Bifidobacterium breve, Bifidobacterium animalis, Lactobacillus acidophilus, Lactobacillus plantarum and Lactobacillus rhamnosus, only the conversion of OA to 10HSA of the isolated protein was shown, but no kinetic data or further characterisation has been reported (Rosberg-Cody et al. 2011; Yang et al. 2013). To make matters worse, in a number of cases, only the activity of cell lysates and whole cells and not data on isolated enzymes were reported: e.g. for Ohy from Chryseobacterium gleum, Desulfobicrobium baculatum and Gemella morbillorum (Schmid et al. 2016).

\section{Phylogeny}

An extensive bioinformatic study to discover and analyse Ohy coding sequences using the BioCatNet database system resulted in the construction of the hydratase engineering database HyED (https://hyed.biocatnet.de/) which contains more than 2000 unique sequences (Schmid et al. 2016). The sequences were categorised on the basis of the amino acid sequence similarity in eleven distinct HFam homologous families. Each HFam family has at least $62 \%$ sequence identity among its members. Besides almost exclusively bacterial genes, only a relatively small number of fungal and archaeal sequences were found, but the enzymes encoded by these genes have not been successfully expressed to date. Among all Ohy's, a conserved FAD binding site, at least in part, can be observed. Interestingly the catalytically important residue Glu122 is replaced by a Methionine in circa $30 \%$ of the sequences, mostly belonging to HFam 1, although HFam 3 family member Rhodococcus erythropolis Ohy ReOhy contains the methionine instead of the conserved glutamate as well. The catalytically important Y241 (EmOhy numbering) is conserved among all Ohy's in the database.

\section{Enzyme activity assays}

Measuring oleate hydratase activity is not trivial, as the solubility of the substrate and product are very low. OA can form micelles, vesicles and other structures in aqueous mixtures (Cistola et al. 1988; Dejanovic et al. 2011; Kaibara et al. 1997; Mele et al. 2018; Suga et al. 2016). The $p K_{a}$ of the carboxylate group of oleic acid is strongly concentration dependent due to neighbouring effects (e.g. in vesicles) ranging from $p K_{a} 5$ to 10 (Kanicky and Shah 2002; Salentinig et al. 2010). At neutral pH, a small amount of sodium oleate will be formed, which can act as an emulsifier (Kaibara et al. 1997). Hence, it is possible that oleic acid/buffer emulsions may be formed. The kinetic parameters that have been previously reported for Ohy have not been corrected for the complex phase behaviour of the substrate OA. Therefore, these parameters (Table 1) should be used with care, as these values are without exception 'apparent' kinetic parameters, and are highly dependent on experimental conditions, such as the use of co-solvents. Although kinetic parameters of Ohy's have been tabulated in several previous review articles, these values are not useful without considering the precise assay conditions.

A number of different activity assay methods have been developed. GC and GC-MS assays have been used in most reports (Table 1). Whole cell samples, cell extracts or isolated enzyme can be incubated with the substrate oleic acid in suspension with or without co-solvents. The product 10-HSA can be extracted using an organic solvent such as ethyl acetate. Subsequently the product is derivatised using silylation to make the product more volatile, e.g. by using $\mathrm{N}, \mathrm{O}$ bis(trimethylsilyl)trifluoroacetamide (BSTFA) as derivatising agent. The derivatised compounds can be separated using an apolar column, such as CP-Sil5 CB, and detected using an FID detector.

Fatty acid analysis using HPLC is well established (Tarola et al. 2012). It is therefore rather surprising that HPLC has been rarely used in literature to measure Ohy reactions. An HPLC method using extraction of fatty acids and derivatisation to phenacyl bromide fatty acid derivatives was successfully used to measure Ohy conversion of OA to 10HSA in two species of ruminal bacteria Selenomonas ruminantium and Enterococcus faecalis (Hudson et al. 

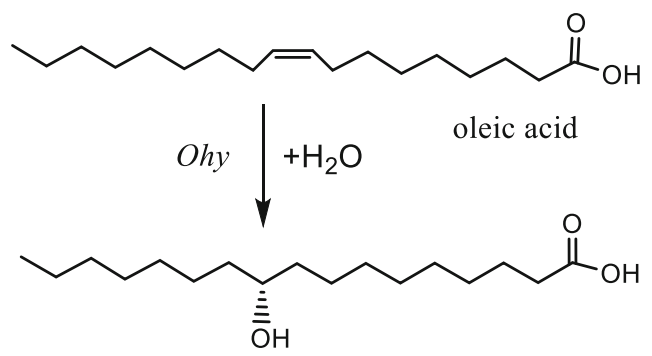

10-hydroxystearic acid

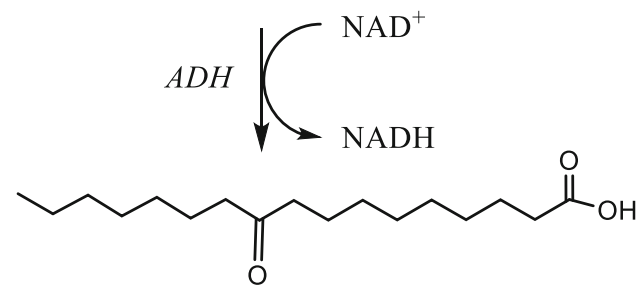

10-ketostearic acid

Scheme 2 Coupled enzymatic UV-vis spectroscopic assay for Ohy activity

1995). Unreacted OA and produced 10-HSA were extracted and dried. Derivatisation was achieved by addition of 2bromoacetophenone and trimethylamine in acetone and incubation at $100^{\circ} \mathrm{C}$ for $15 \mathrm{~min}$. The derivatisation was stopped by the addition of acetic acid, and drying of the samples. The samples were analysed using HPLC with a C18 reversed phase column using UV detection. Recently, an HPLC-MS method to detect hydroxyl fatty acids, including 10-HSA, without a derivatisation step was reported, which could be interesting for measuring Ohy reactions (Kokotou et al. 2020).

The desire for an enzyme assay that can be used in high throughput to facilitate enzyme engineering led to the development of a screening method on the basis of a chemical follow-up reaction by forming chromogenic alkyl nitrites (Hiseni et al. 2014). This assay allowed the distinction between tertiary and primary/secondary alcohols, and was successful for the measurement of Ohy activity in a microtiter plate format, which in principle can be implemented in a high throughput screening platform.

More recently a completely enzymatic coupled UV-vis spectrophotometric assay was developed that was adapted to a high throughput assay (Busch et al. 2020b; Sun et al. 2021). This assay is based on the coupling of the Ohy reaction with the subsequent enzymatic oxidation of 10-HSA to 10ketostearic acid by an $\mathrm{NAD}^{+}$-dependent secondary alcohol dehydrogenase (Scheme 2). This allows the UV-vis spectrophotometric monitoring of NADH production over time as a measure of Ohy activity under the right conditions. The 10HSA oxidation activity was already reported in microbial whole cell reactions (Niehaus et al. 1978), and a number of 10-HSA converting alcohol dehydrogenases have been identified (Huang et al. 2020; Wu et al. 2019). ADH010 and
ADH020 out of a commercial screen of ten different NAD ${ }^{+}$dependent alcohol dehydrogenases (Evoxx, Monheim am Rhein, Germany) were found to convert 10-HSA efficiently (Busch et al. 2020b). By coupling the reaction to the chemical oxidation of NADH by phenazine methosulfate (PMS) coupled to the reduction of MTT (3-(4,5-dimethylthiazol-2yl)-2,5-diphenyltetrazolium bromide) forming its insoluble purple-coloured formazan, a feasible HTS assay was developed (Sun et al. 2021).

Interestingly cooperative kinetics was observed for $R p$ Ohy and $S a$ Ohy, which were the only two enzymes for which the activity was not determined using discontinuous GC assays (Table 1). It remains to be determined if these effects are due to the experimental conditions that were used or reflect true enzyme properties.

\section{Structure}

In 2013, the first structure of an oleate hydratase L. acidophilus Ohy (pdb entry 4ai6, Table 2) (Volkov et al. 2013) was reported. To date, 10 structures of 5 different oleate hydratases have been deposited (Fig. 2). All structures are homodimeric, except for $R$. erythropolis Ohy (pdb 5odo, Table 2). Only two structures contain the FAD cofactor, which is essential for activity, and several structures contain substrate or product.

The structures of oleate hydratase are predominantly homodimeric, with each monomer consisting of four domains (Fig. 2). Three domains form together the FAD and substrate/ product binding sites (domains I-III), and the fourth Cterminal domain (domain IV) provides a hydrophobic substrate access channel. There is structural evidence from L. acidophilus Ohy that the substrate bound conformation of one subunit influences the conformation of the other to facilitate substrate access, which could be consistent with the cooperative kinetics that has been observed in some Ohy's (Volkov et al. 2013). The structure of EmOhy showed a homodimer with one monomer FAD bound and one monomer apo (Engleder et al. 2015). The conserved active site residues Glu122 and Tyr241 (EmOhy numbering) were found to be very important for the hydratase activity. Further evidence for conformational changes in the N-terminal loop region involved in the FAD binding part of the enzyme was provided by the Stenotrophomonas sp. KCTC12332 Ohy structure (Park et al. 2018). In the absence of bound FAD, this region is less structured and more flexible, and may serve as a 'lid' upon binding of the cofactor. The structure of $R$. erythropolis Ohy showed a monomeric protein, rather than the homodimer of all other reported structures (Lorenzen et al. 2018). The monomer has the same four domains as the other Ohy's, although the C-terminal domain four is significantly shorter, lacking an alpha-helix involved in the dimerisation in the case of the other Ohy's. This domain undergoes a large 
Table 2 Structures of oleate hydratases

\begin{tabular}{|c|c|c|c|c|c|}
\hline Organism & Name & Type & pdb entry & Remarks & Reference \\
\hline Elisabethkingia meningoseptica & EmOhy & HFam 11 & 4uir & FAD bound & (Engleder et al. 2015) \\
\hline \multirow[t]{2}{*}{ Lactobacillus acidophilus } & \multirow[t]{2}{*}{ LaOhy } & \multirow[t]{2}{*}{ HFam 2} & $4 \mathrm{ia} 5$ & apo & \multirow[t]{2}{*}{ (Volkov et al. 2013) } \\
\hline & & & $4 \mathrm{ia6}$ & Substrate bound ${ }^{\mathrm{a}}$ & \\
\hline Rhodococcus erythropolis & ReOhy & HFam 3 & 5odo & apo & (Lorenzen et al. 2018) \\
\hline \multirow[t]{5}{*}{ Staphylococcus aureus } & \multirow[t]{5}{*}{ SaOhy } & \multirow[t]{5}{*}{ HFam 11} & $7 \mathrm{kaz}$ & E82A, substrate, product ${ }^{\mathrm{b}}$ and FAD bound & \multirow[t]{5}{*}{ (Radka et al. 2021) } \\
\hline & & & $7 \mathrm{kav}$ & PEG bound & \\
\hline & & & $7 \mathrm{kaw}$ & PEG and FAD bound & \\
\hline & & & $7 \mathrm{kax}$ & E82A & \\
\hline & & & 7 kay & E82A and substrate ${ }^{\mathrm{c}}$ bound & \\
\hline Stenotrophomonas sp. KCTC 12332 & StOhy & HFam 11 & $5 z 70$ & apo & (Park et al. 2018) \\
\hline
\end{tabular}

${ }^{\mathrm{a}}$ Linoleic acid, ${ }^{\mathrm{b}}$ 10-HSA, ${ }^{\mathrm{c}} \mathrm{OA}$

conformational change upon substrate binding. Interestingly the conserved glutamate residue of most Ohy's was replaced by a methionine (M77 ReOhy numbering). The M77E variant of ReOhy showed a 5-fold reduction in activity compared to the WT enzyme, which indicates a distinct mechanism for this enzyme and possibly other HFam 3 type enzymes.
Fig. 2 Overview of the structures of oleate hydratases showing the dimeric and monomer structures (top) and the domain organisation (bottom): domain I (orange), domain II (green), domain III (purple) and domain IV (yellow). For SaOhy, the domains are as follows: FAD lobe (orange), fatty acid lobe (blue) and C-terminal domain (yellow). The following pdb files were used: EmOhy, 4uir; LaOhy, 4ia6; ReOhy, 5odo; SaOhy, 7kaz; StOhy, 5z70. The images were created using PyMOL

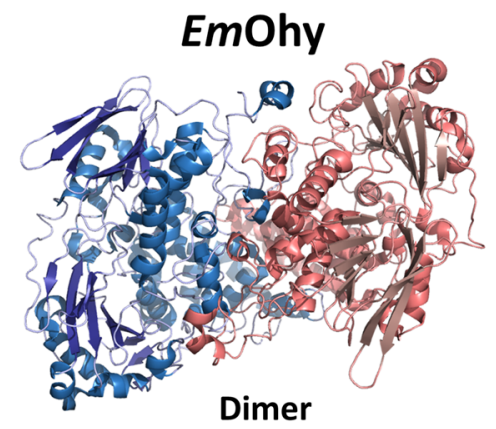

Dimer

\section{ReOhy}
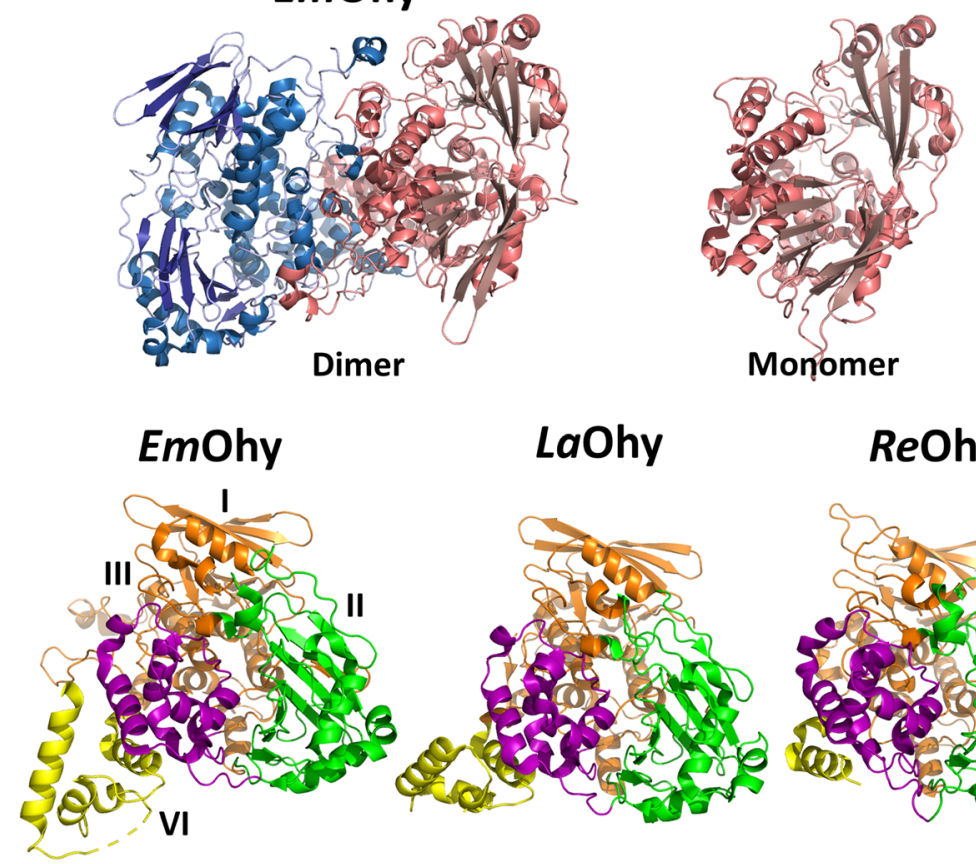

SaOhy FAD lobe

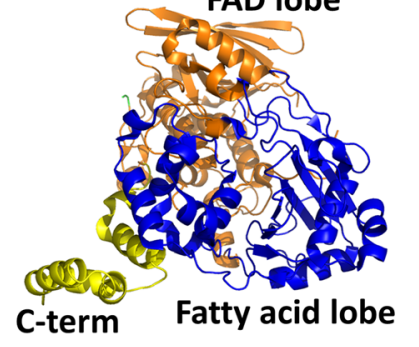

LaOhy

ReOhy

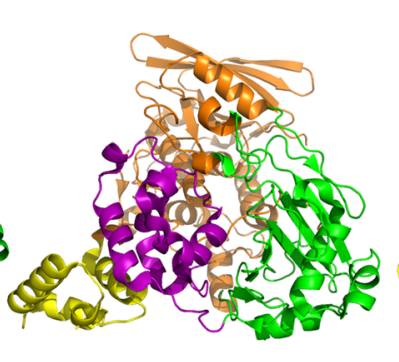

StOhy

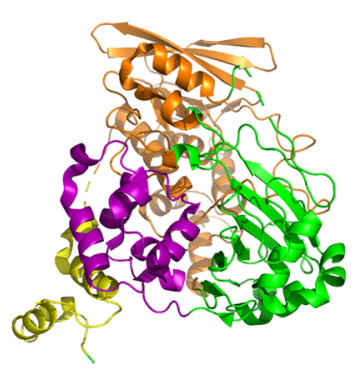

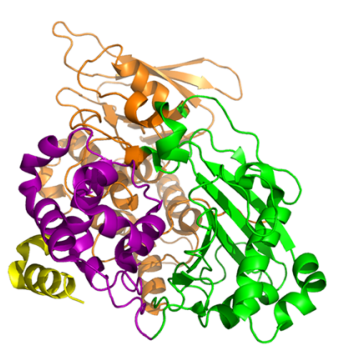


The most complete structures have been obtained for $S$. aureus SaOhy with OA and 10-HSA bound and with the FAD cofactor bound as well (Fig. 3) (Radka et al. 2021). $\operatorname{Arg} 81$ ( $\mathrm{SaOhy}$ numbering) was found to serve as a 'gatekeeper' residue involved in the proper orientation of the fatty acid substrate. This structure led to an important revision of the proposed catalytic mechanism, which will be discussed below. Although the overall structure of the $S a$ Ohy is similar to the other Ohy's, the structure was divided in three 'functional' domains rather than the four 'structural' domains (I to IV) that are described above. The three domains were named: FAD-lobe (domain I), fatty acid lobe (II and III) and Cterminal domain (IV) (Fig. 2).

\section{Catalytic mechanism}

Based on the structure of EmOhy (Fig. 3), a catalytic mechanism has been proposed (Scheme 3 ) involving the protonation of the $\mathrm{CC}$ double bond by the conserved active site tyrosine (Y241 in EmOhy, equivalent to Y201 in SaOhy), with subsequent nucleophilic attach of water, supported by deprotonation using the conserved glutamate (E122 in EmOhy, equivalent to E82 in $\mathrm{SaOhy}$ (Engleder et al. 2015). The function of the FAD cofactor, most likely $\mathrm{FADH}_{2}$, was proposed to be structural and to stabilise the transient positive charge on the substrate after the protonation step.

This mechanism has recently been superseded by a new one due to structural information of SaOhy (Fig. 3). A mechanism based on acid-base catalysis involving careful positioning of the substrate water and the fatty acids assisted by the FAD cofactor has been proposed (Radka et al. 2021). The conserved active site Glutamate (E122 in EmOhy and E82 in $\mathrm{SaOhy}$ ) is involved in stabilising the substrate water molecule as a hydronium ion (Scheme 3). The $\mathrm{H}^{+}$from the hydronium ion attack the $\mathrm{CC}$ double bond producing a transient carbocation intermediate, which is subsequently attacked by the water to form the hydrated product. In this mechanism, FAD predominantly functions to expel most water molecules from the active site, and to properly orient the important residues Glu82 and Arg81 facilitating the proper order of the mechanistic steps. FAD does not form a stable prosthetic group for this enzyme but it released to facilitate product release. The potential role of the conserved tyrosine Y201 (Y241 in EmOhy) in the catalytic mechanism as proposed by Engleder et al. is questionable as the tyrosyl oxygen forms a hydrogen bound with the backbone carbonyl of V505 in all structures of SauOhy, with or without substrate or product bound. This excludes the deprotonation of this tyrosine as the first step of the mechanism. The tyrosine is involved in a hydrogen bonding network that stabilised the bound product, and SauOhy Y201F was found to still stereoselectively add water to $\mathrm{OA}$, albeit at a 10 -fold reduction of the rate.
The mechanism of ReOhy (HFam 3), which has a methionine (M77 ReOhy numbering) instead of the conserved active site glutamate, remains to be resolved. Perhaps another active site residue can take over the role to activate the water molecule. This at least indicates that there may be different catalytic mechanisms for the oleate hydratases, which may hold for different HFam types.

\section{Substrate scope}

Already for the original microbial activity of oleate hydratase (more generally fatty acid hydratase) and later for the isolated enzymes and expressed enzyme containing $E$. coli lysates, it was clearly shown that the enzyme is capable of hydrating a number of different $\omega-9$ unsaturated fatty acids, including oleic acid (C18:1), palmitoleic acid (C16:1), myristoleic acid (C14:1) and linoleic acid (C18:2) (Scheme 4) (Hou 1995). In almost all cases, the product has the $\mathrm{OH}$ group on the $\mathrm{C} 10$ position, although for certain substrates, $\mathrm{C} 13$ has also been reported (Eser et al. 2020). Depending on the preferred substrate, some of the reported oleate hydratases may have to be renamed for example as a linoleic acid hydratase. It is clear that there is overlapping substrate specificity among fatty acid hydratases. A study of two distinct Ohys from Rhodococcus species showed that the enzymes have a complementary substrate scope, for which some substrates were only converted by $R e$ Ohy and some only by RpOhy (Busch et al. 2020b). This confirms that protein engineering has potential to direct the substrate preference.

\section{Biotechnological applications of oleate hydratase}

\section{Production of hydroxy fatty acids}

Already since the discovery of the microbial Ohy activity in the 1960s, applications to produce hydroxyl fatty acids have been reported (Hou 1995; Koritala et al. 1989). Since the coding gene and structure are uncovered, tailored engineering has become feasible, which has increased the development of improved enzymes and approaches to enhance the substrate scope. Eser et al. showed that targeted mutations can influence the substrate specificity and regioselectivity of two related Ohy's from L. acidophilius (Eser et al. 2020). The productivity of different enzyme systems for the hydration of different fatty acids has been reviewed excellently by Löwe and Gröger (Löwe and Gröger 2020). Space-time yields (STYs) for the production of 10-HSA ranging from 8 to $384 \mathrm{~g} \mathrm{~L}^{-1} \mathrm{~h}^{-1}$ have been reported. Bioprocess engineering of an $E$. coli strain overexpressing StOhy resulted in a 10-HSA productivity of $46 \mathrm{~g} / \mathrm{L}$ culture (Jeon et al. 2012). 

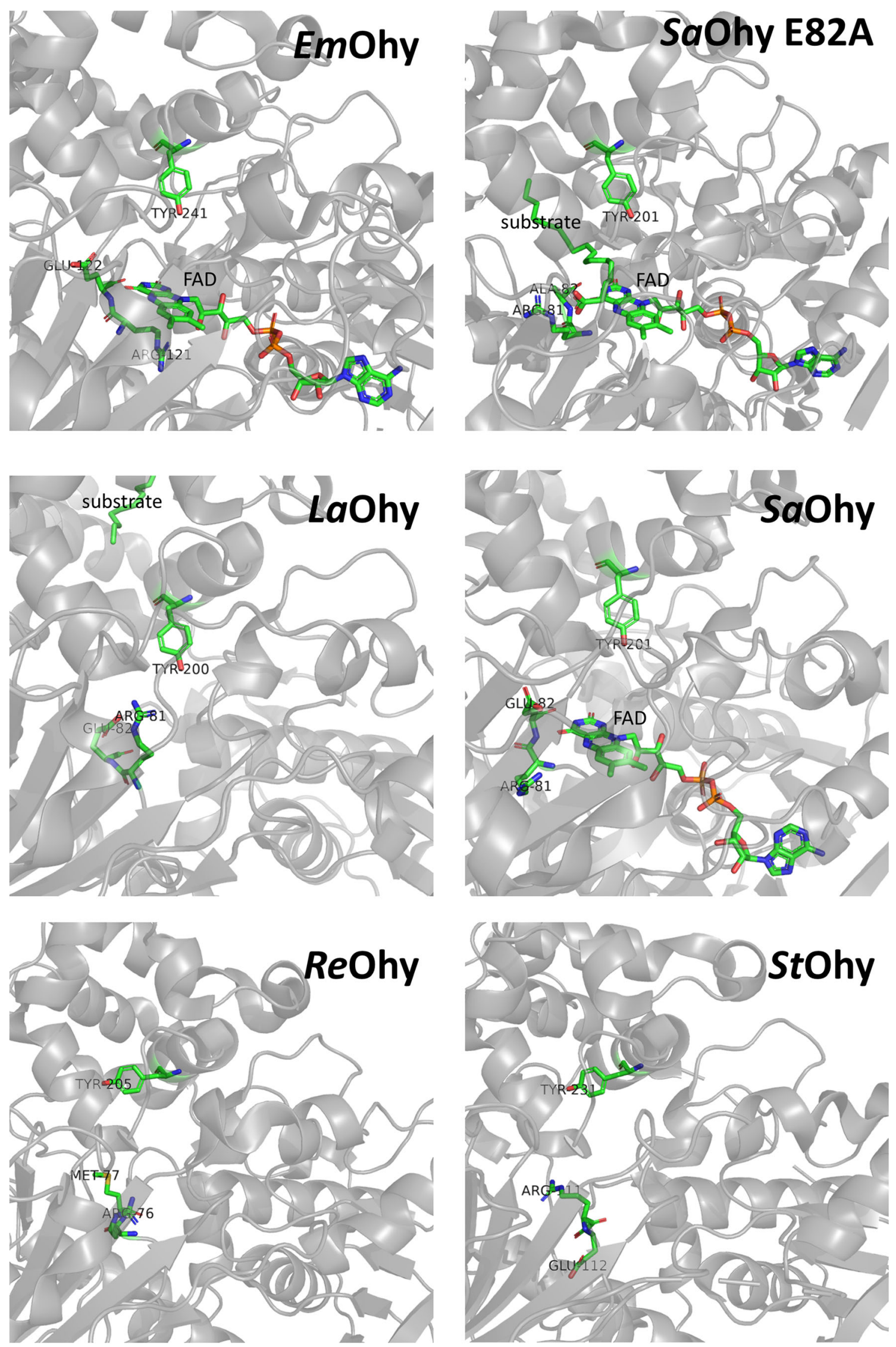
Fig. 3 Active site structures of oleate hydratases with and without bound FAD and substrate. Important active site aminoacids are indicated. The following pdb files were used: EmOhy, 4uir; LaOhy, 4ia6; ReOhy, 5odo; $\mathrm{SaOhy}, 7 \mathrm{kaw}$; $\mathrm{SaOhy}$ E82A, 7kaz; StOhy, 5z70. The images were created using PyMOL

The substrate scope of Ohy can be enhanced by using socalled decoy molecules. Hauer and co-workers used hexanoic acid as a short 'decoy' carboxylic acid, to allow the selective hydration of short chain alkenes by EmOhy (Demming et al. 2019). Site-directed mutagenesis of a small hydrophobic amino acid A248 close to the active site improved the productivity. Though still in its infancy, this approach offers a very promising approach for the stereoselective hydration of a broader range of terminal and other non-activated $\mathrm{C}=\mathrm{C}$-double bonds. Hopefully, further improvements will turn this methodology truly practical for organic synthesis.

\section{Engineering Ohy for 10-HSA production}

Rational mutagenesis of amino acids involved in the substrate binding site of EmOhy resulted in variants with improved conversion in whole cell reactions after $96 \mathrm{~h}$ of OA derivatives in which the carboxylate group was replaced by different esters, alcohol, hydroxamic acid or amide groups (Engleder et al. 2019). For example, EmOhy Q265A/T436A/N438A exhibited a 17.6-fold higher conversion rate for the propyl ester of OA compared to the WT enzyme, albeit with a low overall yield of $4 \%$. This shows that the substrate scope of Ohy's can be significantly enhanced using protein engineering.

Variants of Paracoccus aminophilus Ohy produced by directed evolution were found to have enhanced OA conversion activity and stability under particular reaction conditions (Sun et al. 2021). This was possible by the development of the enzymatic colorimetric high-throughput screening assay discussed above. Site-saturation mutagenesis of important active site residues resulted in only one improved variant. By combining different successful amino acid substitutions, the triple mutant F122L/F233L/T15N was obtained that exhibited a 4-fold higher $k_{c a t}$, at a similar $K_{M}$ compared to the WT enzyme. On the basis of a homology model of the structure of $P a$ Ohy, the molecular basis of the beneficial mutations was attributed to increasing hydrogen bonding interactions in different sites in the protein. Using the enzymatic cascade of Ohy and Micrococcus luteus secondary alcohol dehydrogenase, a STY of $540 \mathrm{~g} \mathrm{~L}^{-1}$ day $^{-1}$ of 10-HSA and 10-ketostearic acid was obtained.

\section{Multi-step reactions to broaden the product scope}

Hydroxylated fatty acids are interesting products with a range of applications as cosmetic ingredients or as antimicrobial active compounds. Beyond this, hydroxyl fatty acids also serve as building blocks for the synthesis of other chemical intermediates. For this, a range of cascade reactions involving further enzymatic conversion steps after the Ohy-catalysed double bond hydration have been designed. Especially Park and coworkers have pioneered a range of interesting cascades (Song et al. 2013; Song et al. 2014; Song et al. 2020). The first step in most of these cascades comprises the oxidation of the newly formed alcohol into the corresponding ketone as catalysed for example by the secondary alcohol dehydrogenase (ADH) from Lactobacillus delbrueckii or M. luteus (Seo et al. 2019b; Wu et al. 2019). Performing this reaction in a
Scheme 3 The reaction mechanisms that have been proposed for EmOhy (top) and SaOhy (bottom)
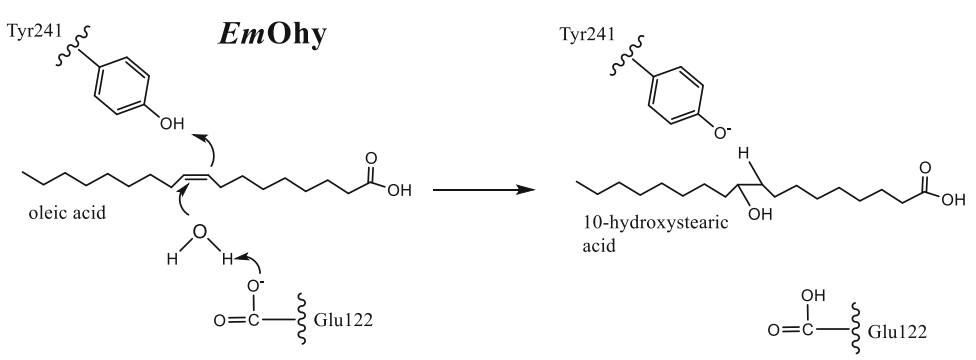

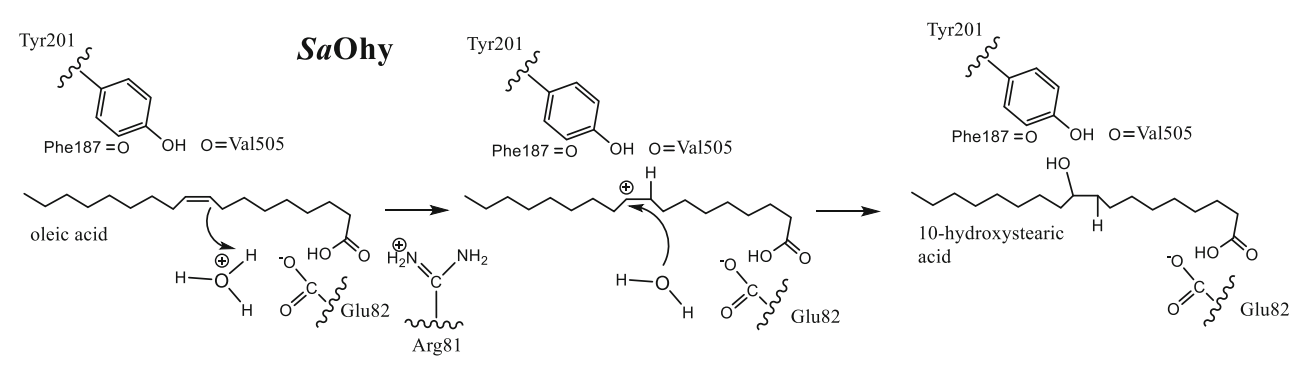



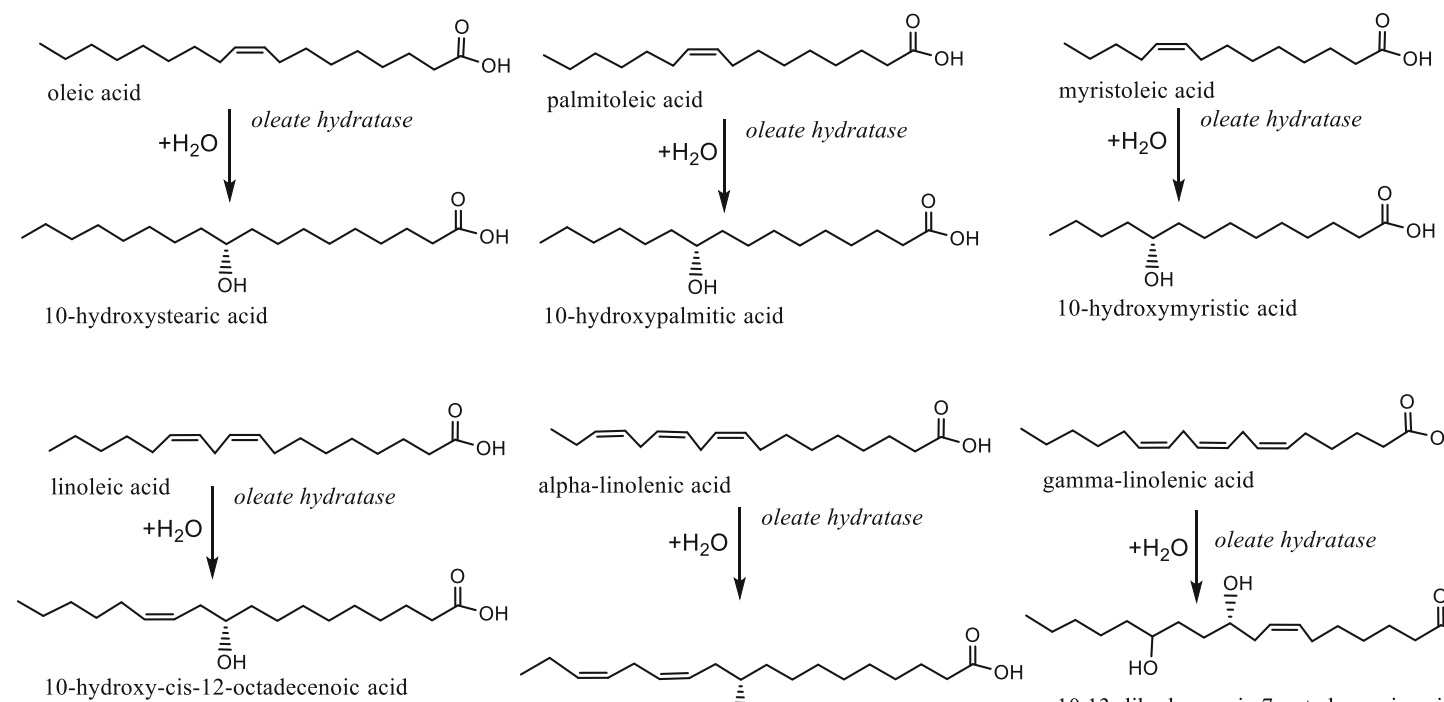

alpha-linolenic acid

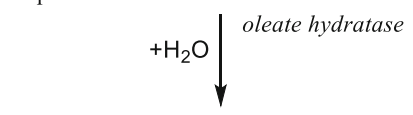

10-hydroxy-cis-12-octadecenoic acid
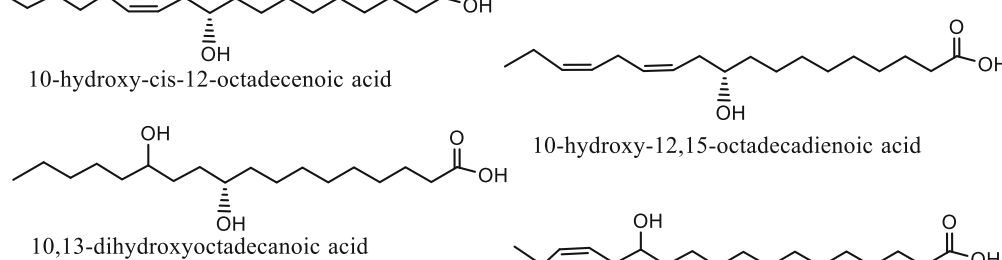

10-hydroxy-12,15-octadecadienoic acid
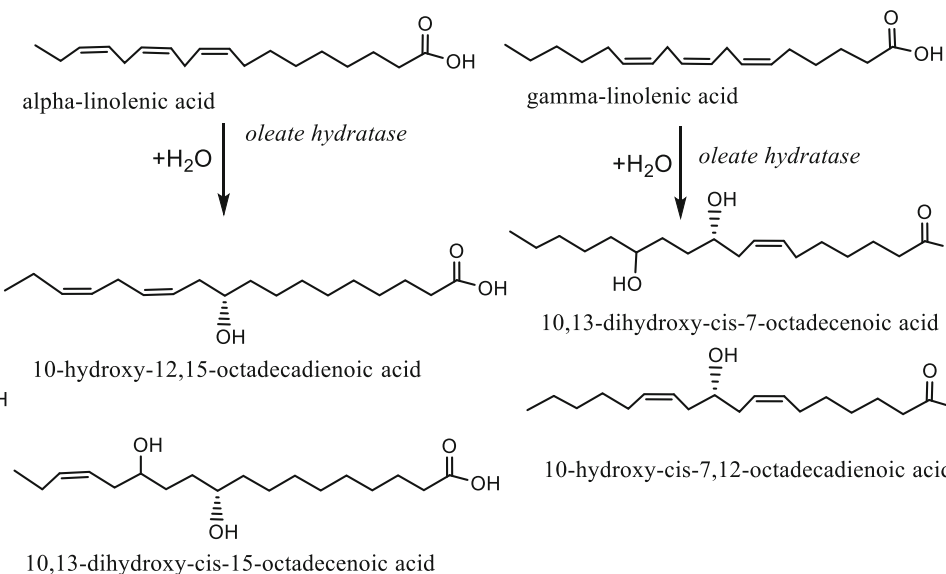

gamma-linolenic acid
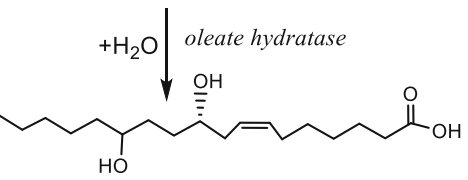

10,13-dihydroxy-cis-7-octadecenoic acid

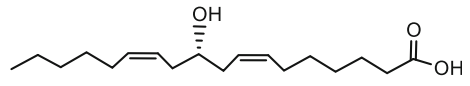

10-hydroxy-cis-7,12-octadecadienoic acid

10,13-dihydroxy-cis-15-octadecenoic acid

Scheme 4 Substrate scope of oleate hydratases

cell-free environment requires in situ regeneration of the oxidised nicotinamide cofactor, which can be achieved, e.g. by employing lactate dehydrogenase-catalysed reduction of pyruvic acid (NADH-dependent and $\mathrm{NAD}^{+}$-forming). Due to opposing $\mathrm{pH}$ optima of the hydration and the oxidation step, this reaction was performed in a one-pot two-step fashion including a $\mathrm{pH}$ switch between both reactions. Nevertheless, a STY of $217 \mathrm{~g} \mathrm{~L}^{-1}$ day $^{-1}$ was obtained (using $5 \mathrm{~g} / \mathrm{L} \mathrm{PaOhy}$ and $0.25 \mathrm{~g} / \mathrm{L}$ lyophylised cell extract of the other enzymes).

The resulting keto fatty acids can be further transformed further into useful products (Scheme 5). For example, esters can be obtained using Baeyer-Villiger oxidases (BVMOs) (Song et al. 2013). Depending on the selectivity of the $\mathrm{BVMO}$ used, the $\mathrm{O}$ atom can be inserted either on the carboxy terminal substituent of the keto group or on its alkyl terminal side. As a result, after hydrolase-catalysed cleavage of the esters, either dicarboxylic acids or $\omega$-hydroxy carboxylic acids (together with the primary alcohols formed during the hydrolysis) can be obtained (Seo et al. 2018; Song et al. 2014). Both products are interesting, bio-based building blocks for polyesters. Another possibility of further valorising the OhyADH-derived fatty acid ketones is to perform a transaminasecatalysed reductive aminations yielding fatty amines. By engineering the $\mathrm{NAD}^{+}$-dependent $\mathrm{ADH}$ from $M$. luteus to a more effective $\mathrm{NADP}^{+}$-dependent enzyme, a redox neutral bi-enzymatic cascade with the NADPH-dependent BVMO was obtained (Seo et al. 2019b).

Co-expression of the Ohy, ADH and BVMO in E.coli resulted in an effective whole cell biocatalyst containing the whole cascade (Seo et al. 2019a). By optimising the protein expression and by using an engineered BVMO, a yield of $n$ nonanoic acid and 9-hydroxynonnoic acid of $6 \mathrm{mmol} / \mathrm{g}$ dry cells was obtained. Another effective strategy based on the same cascade was to combine different whole cell biocatalysts and cell free enzymes in one pot for the production of $\mathrm{C} 11$ nylon monomers (undecanedioic acid and 11aminoundecanoic acid) from ricinoleic acid (12-hydroxy-9cis-octadecenoic acid) (Kim et al. 2020). The key for the effective biotransformation was to use adsorbent polymeric beads (Sepabeads S825) to bind the hydroxyl fatty acid and products, which ameliorated their enzyme inhibitory effects.

More recently, the aforementioned cascades have been extended by use of a new, photoactivated fatty acid decarboxylase from Chlorella variabilis ( $C v \mathrm{FAP})$ (Sorigué et al. 2017). Combining both enzymes enabled the transformation of a range of unsaturated fatty acids into secondary alcohols (Zhang et al. 2020a). This cascade had to be performed in a one-pot two-step fashion in order to avoid the $C v$ FAPcatalysed decarboxylation of the unsaturated fatty acid starting materials. $C v \mathrm{FAP}$ can also be used to decarboxylate the products obtained through the LdADH/BVMO or LdADH/TA cascades (Scheme 5) (Cha et al. 2020).

Another expansion of the scope of Ohy in biotransformations is the production of fatty acid esters of hydroxyl fatty acids (FAHFAs). FAHFAs are bioactive compounds with therapeutic potential, e.g. for the treatment of diabetes. Guo and co-workers were able to create a bi-enzymatic cascade containing LaOhy and Candida Antarctica lipase A (CalA) 


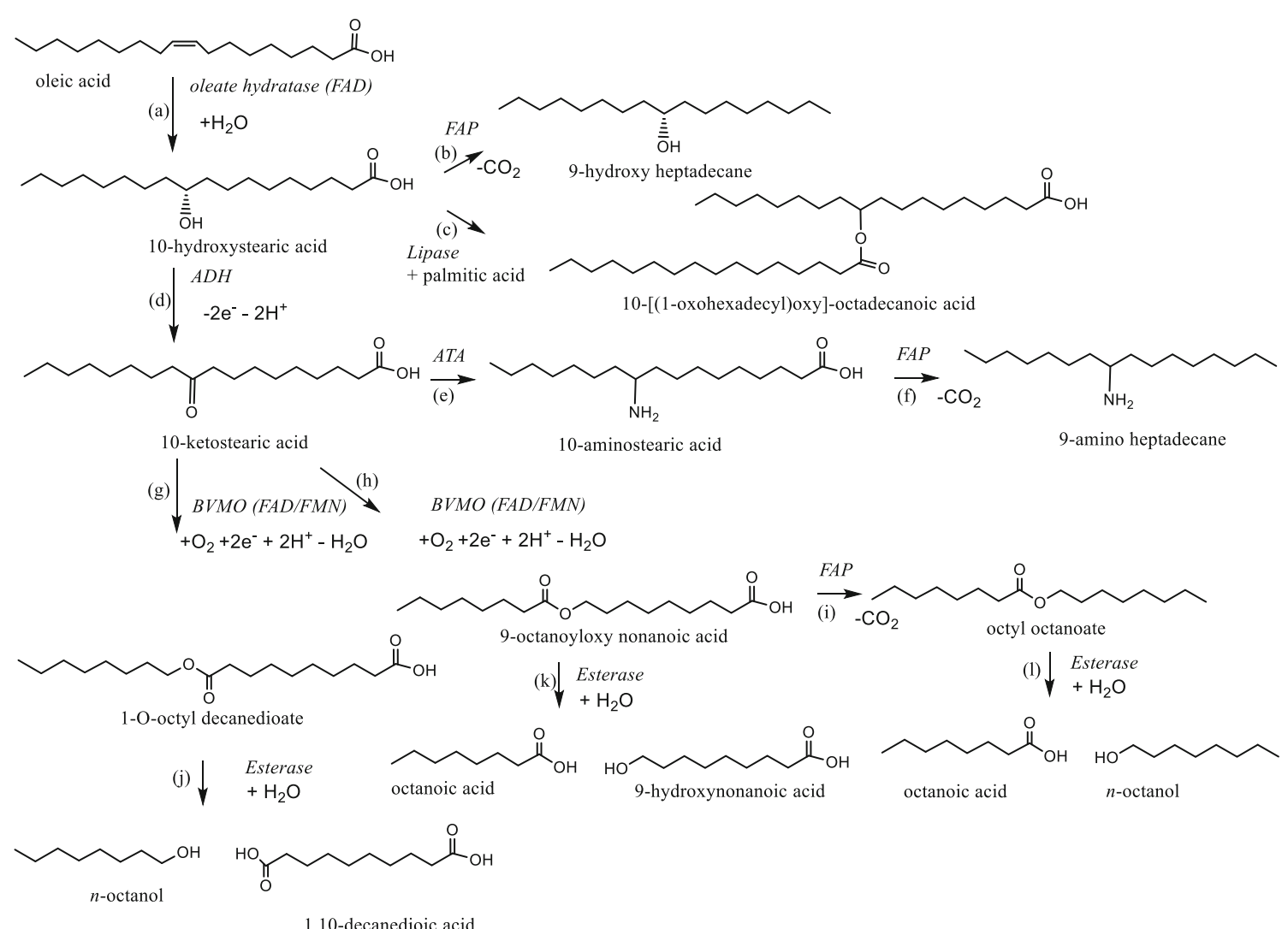

Scheme 5 Overview of biocatalytic cascades with Ohy. FAP, fatty acid photodecarboxylase; ATA, amine transaminase; BVMO, Baeyer-Villiger monooxygenase. a Oleate hydratase-catalysed hydration of oleic acid to 10-hydroxystearic acid, b FAP-catalysed decarboxylation of 10-HSA to 9-hydroxy heptadecane, $\mathbf{c}$ lipase-catalysed esterification of 10-HSA to the FAHFA 10-[(1-oxohexadecyl)oxy]-octadecanoic acid, d secondary alcohol dehydrogenase-catalysed oxidation of 10-HSA to 10-ketostearic acid, e transamination catalysed by amine transaminase of 10-ketostearic acid to 10 -aminostearic acid, $\mathbf{f}$ decarboxylation of 10 -aminostearic acid to 9 -

to generate different FAHFAs (Zhang et al. 2021). Using the LaOhy and CalA in a one-pot biphasic system with oleic acid and palmitic acid as substrate, the palmitate ester of 10-HSA (10-[(1-oxohexadecyl)oxy]-octadecanoic acid) was obtained with $48 \%$ conversion and $25 \%$ isolated yield.

\section{Immobilisation of Ohy}

The immobilisation of enzymes is performed to improve their stability, to allow for reaction engineering (organic solvents or continuous reactions) and recuperation and reuse (Hanefeld 2013; Hanefeld et al. 2009). With these targets in mind, oleate hydratase was immobilised onto different carrier materials covalently as well as via non-covalent approaches, in the presence or absence of additives. The additives lead to initially higher activity; however, this might also be ascribed to the altered reaction conditions in their presence as discussed above. All immobilisation procedures lead to a significant loss of activity. This might be due to the fact that in all procedures amino heptadecane, $\mathbf{g}$ BVMO-catalysed oxidation of 10-ketostearic acid to 1-O-octyl decanedioate, h BVMO-catalysed oxidation of 10 ketostearic acid to 9-octanoyloxy nonanoic acid, i FAP-catalysed decarboxylation of 9-octanoyloxy nonanoic acid to octyl octanoate, $\mathbf{j}$ esterasecatalysed hydrolysis of $1-O$-octyl decanedioate to $n$-octanol and 1,10 decanedioic acid, $\mathbf{k}$ esterase-catalysed hydrolysis of 9-octanoyloxy nonanoic acid to octanoic acid and 9-hydroxynonanoic acid, and $\mathbf{l}$ esterase-catalysed hydrolysis of octyl octanoate to octanoic acid and $n$ octanol

involved several washing steps, leading to a loss of the essential FAD. Adsorption on Celite 545, ionic interactions with chitosan and coordination via the his tag yielded disappointing results, as did straightforward cross-linking to form a crosslinked enzyme aggregate (CLEA). Sol-gel entrapments with many variations resulted in complete deactivation. However, covalent attachment onto magnetic chitosan composite macro-particles was successful with a recovery of activity of $24 \%$ and enhanced enzyme stability. The easy to handle particles could be recycled 5 times with minor loss of activity in batch reactions (Todea et al. 2015).

Author contribution PLH, FH and UH wrote the review. PLH edited and designed the structure of the review.

Funding This study was funded by the Netherlands Organisation for Scientific Research (NWO) domain Applied and Engineering Sciences (grant 14170). 


\section{Declarations}

Ethics approval This article does not contain any studies with human participants or animals performed by any of the authors.

Conflict of interest The authors declare no competing interests.

Open Access This article is licensed under a Creative Commons Attribution 4.0 International License, which permits use, sharing, adaptation, distribution and reproduction in any medium or format, as long as you give appropriate credit to the original author(s) and the source, provide a link to the Creative Commons licence, and indicate if changes were made. The images or other third party material in this article are included in the article's Creative Commons licence, unless indicated otherwise in a credit line to the material. If material is not included in the article's Creative Commons licence and your intended use is not permitted by statutory regulation or exceeds the permitted use, you will need to obtain permission directly from the copyright holder. To view a copy of this licence, visit http://creativecommons.org/licenses/by/4.0/.

\section{References}

Bevers LE, Pinkse MWH, Verhaert PDEM, Hagen WR (2009) Oleate hydratase catalyzes the hydratation of a nonactivated carbon-carbon bond. J Bacteriol 191(15):5010-5012. https://doi.org/10.1128/JB. 00306-09

Busch H, Alvarenga N, Abdelraheem E, Hoek M, Hagedoorn P-L, Hanefeld U (2020a) Re-investigation of hydration potential of Rhodococcus whole-cell biocatalysts towards Michael acceptors. ChemCatChem 12(1):193-198. https://doi.org/10.1002/cctc. 201901606

Busch H, Tonin F, Alvarenga N, van den Broek M, Lu S, Daran J-M, Hanefeld U, Hagedoorn P-L (2020b) Exploring the abundance of oleate hydratases in the genus Rhodococcus - discovery of novel enzymes with complementary substrate scope. Appl Microbiol Biotechnol 104(13):5801-5812. https://doi.org/10.1007/s00253020-10627-7

Cha H-J, Hwang S-Y, Lee D-S, Kumar AR, Kwon Y-U, Voß M, Schuiten E, Bornscheuer UT, Hollmann F, Oh D-K, Park J-B (2020) Whole-cell photoenzymatic cascades to synthesize longchain aliphatic amines and esters from renewable fatty acids. Angew Chem Int Ed Engl 59(18):7024-7028. https://doi.org/10. 1002/anie.201915108

Chen B-S, Otten LG, Hanefeld U (2015) Stereochemistry of enzymatic water addition to $\mathrm{C}=\mathrm{C}$ bonds. Biotechnol Adv 33(5):526-546. https://doi.org/10.1016/j.biotechadv.2015.01.007

Cistola DP, Hamilton JA, Jackson D, Small DM (1988) Ionization and phase behavior of fatty acids in water: application of the Gibbs phase rule. Biochemistry 27(6):1881-1888. https://doi.org/10.1021/ bi00406a013

Davis EN, Wallen LL, Goodwin JC, Rohwedder WK, Rhodes RA (1969) Microbial hydration of cis-9-alkenoic acids. Lipids 4(5):356-362. https://doi.org/10.1007/bf02531006

Dejanovic B, Noethig-Laslo V, Sentjurc M, Walde P (2011) On the surface properties of oleate micelles and oleic acid/oleate vesicles studied by spin labeling. Chem Phys Lipids 164:83-88. https://doi. org/10.1016/j.chemphyslip.2010.11.002

Demming RM, Fischer M-P, Schmid J, Hauer B (2018) (De)hydratases - recent developments and future perspectives. Curr Opin Chem Biol 43:43-50. https://doi.org/10.1016/j.cbpa. 2017.10.030
Demming RM, Hammer SC, Nestl BM, Gergel S, Fademrecht S, Pleiss J, Hauer B (2019) Asymmetric enzymatic hydration of unactivated, aliphatic alkenes. Angew Chem Int Ed Engl 58(1):173-177. https://doi.org/10.1002/anie.201810005

Engleder M, Pichler H (2018) On the current role of hydratases in biocatalysis. Appl Microbiol Biotechnol 102(14):5841-5858. https://doi. org/10.1007/s00253-018-9065-7

Engleder M, Pavkov-Keller T, Emmerstorfer A, Hromic A, Schrempf S, Steinkellner G, Wriessnegger T, Leitner E, Strohmeier GA, Kaluzna I, Mink D, Schurmann M, Wallner S, Macheroux P, Gruber K, Pichler H (2015) Structure-based mechanism of oleate hydratase from Elizabethkingia meningoseptica. ChemBioChem 16(12): 1730-1734. https://doi.org/10.1002/cbic.201500269

Engleder M, Strohmeier GA, Weber H, Steinkellner G, Leitner E, Müller M, Mink D, Schürmann M, Gruber K, Pichler H (2019) Evolving the promiscuity of Elizabethkingia meningoseptica oleate hydratase for the regio- and stereoselective hydration of oleic acid derivatives. Angew Chem Int Ed Engl 58(22):7480-7484. https://doi.org/10. 1002/anie.201901462

Eser BE, Poborsky M, Dai R, Kishino S, Ljubic A, Takeuchi M, Jacobsen C, Ogawa J, Kristensen P, Guo Z (2020) Rational engineering of hydratase from Lactobacillus acidophilus reveals critical residues directing substrate specificity and regioselectivity. ChemBioChem 21:550-563. https://doi.org/10.1002/cbic.201900389

Hanefeld U (2013) Immobilisation of hydroxynitrile lyases. Chem Soc Rev 42(15):6308-6321. https://doi.org/10.1039/C3CS35491A

Hanefeld U, Gardossi L, Magner E (2009) Understanding enzyme immobilisation. Chem Soc Rev 38(2):453-468. https://doi.org/10.1039/ B711564B

Hiseni A, Medici R, Arends IWCE, Otten LG (2014) Enzymatic hydration activity assessed by selective spectrophotometric detection of alcohols: a novel screening assay using oleate hydratase as a model enzyme. Biotechnol J 9(6):814-821. https://doi.org/10.1002/biot. 201300412

Hou CT (1995) Microbial oxidation of unsaturated fatty acids. In: Neidleman SL, Laskin AI (eds) Adv Appl Microbiol, vol 41. Academic Press, pp 1-23

Huang J-K, Samassekou K, Alhmadi HB, VanDerway DR, Diaz JD, Seiver JA, McClenahan SW, Holt SM, Wen L (2020) Knockout of secondary alcohol dehydrogenase in Nocardia cholesterolicum NRRL 5767 by CRISPR/Cas9 genome editing technology. PLoS ONE 15(3):e0230915. https://doi.org/10.1371/journal.pone. 0230915

Hudson JA, MacKenzie CAM, Joblin KN (1995) Conversion of oleic acid to 10-hydroxystearic acid by two species of ruminal bacteria. Appl Microbiol Biotechnol 44(1):1-6. https://doi.org/10.1007/ BF00164472

Jeon E-Y, Lee J-H, Yang K-M, Joo Y-C, Oh D-K, Park J-B (2012) Bioprocess engineering to produce 10-hydroxystearic acid from oleic acid by recombinant Escherichia coli expressing the oleate hydratase gene of Stenotrophomonas maltophilia. Process Biochemistry 47(6):941-947. https://doi.org/10.1016/j.procbio. 2012.03.002

Joo YC, Jeong KW, Yeom SJ, Kim YS, Kim Y, Oh DK (2012) Biochemical characterization and FAD-binding analysis of oleate hydratase from Macrococcus caseolyticus. Biochimie 94:907-915. https://doi.org/10.1016/j.biochi.2011.12.011

Kaibara K, Iwata E, Eguchi Y, Suzuki M, Maeda H (1997) Dispersion behaviour of oleic acid in aqueous media: from micelles to emulsions. Colloid Poly Sci 275:777-783. https://doi.org/10.1007/ s003960050147

Kang W-R, Seo M-J, Shin K-C, Park J-B, Oh D-K (2017a) Comparison of biochemical properties of the original and newly identified oleate hydratases from Stenotrophomonas maltophilia. Appl Environ Microbiol 83(9):e03351-e03316. https://doi.org/10.1128/AEM. 03351-16 
Kang W-R, Seo M-J, Shin K-C, Park J-B, Oh D-K (2017b) Gene cloning of an efficiency oleate hydratase from Stenotrophomonas nitritireducens for polyunsaturated fatty acids and its application in the conversion of plant oils to 10-hydroxy fatty acids. Biotechnol Bioeng 114(1):74-82. https://doi.org/10.1002/bit.26058

Kanicky JR, Shah D (2002) Effect of degree, type, and position of unsaturation on the $p K_{a}$ of long-chain fatty acids. J Coll Int Sci 256:201-207. https://doi.org/10.1006/jcis.2001.8009

Kil KS, Cunningham MW, Barnett LA (1994) Cloning and sequence analysis of a gene encoding a 67-kilodalton myosin-cross-reactive antigen of Streptococcus pyogenes reveals its similarity with class II major histocompatibility antigens. Infect Immun 62(6):2440-2449. https://doi.org/10.1128/IAI.62.6.2440-2449.1994

Kim BN, Joo YC, Kim YS, Kim KR, Oh DK (2012) Production of 10hydroxystearic acid from oleic acid and olive oil hydrolyzate by an oleat hydratase from Lysinibacillus fusiformis. Appl Microbiol Biotechnol 95:929-937. https://doi.org/10.1007/s00253-011-3805-

Kim T-H, Kang S-H, Han J-E, Seo E-J, Jeon E-Y, Choi G-E, Park J-B, Oh D-K (2020) Multilayer engineering of enzyme cascade catalysis for one-pot preparation of nylon monomers from renewable fatty acids. ACS Catal 10(9):4871-4878. https://doi.org/10.1021/ acscatal.9b05426

Kokotou MG, Mantzourani C, Bourboula A, Mountanea OG, Kokotos G (2020) A liquid chromatography-high resolution mass spectrometry (LC-HRMS) method for the determination of free hydroxy fatty acids in cow and goat milk. Molecules 25(17):3947. https://doi. org $/ 10.3390 /$ molecules 25173947

Koritala S, Hou CT, Hesseltine CW, Bagby MO (1989) Microbial conversion of oleic acid to 10-hydroxystearic acid. Appl Microbiol Biotechnol 32(3):299-304. https://doi.org/10.1007/BF00184978

Lorenzen J, Driller R, Waldow A, Qoura F, Loll B, Brück T (2018) Rhodococcus erythropolis oleate hydratase: a new member in the oleate hydratase family tree-biochemical and structural studies. ChemCatChem 10(2):407-414. https://doi.org/10.1002/cctc. 201701350

Löwe J, Gröger H (2020) Fatty acid hydratases: versatile catalysts to access hydroxy fatty acids in efficient syntheses of industrial interest. Catalysts 10(3):287. https://doi.org/10.3390/catal10030287

Mele S, Söderman O, Ljusberg-Wahrén H, Thuresson K, Monduzzi M, Nylander T (2018) Phase behavior in the biologically important oleic acid/sodium oleate/water system. Chem Phys Lipids 211:30 36. https://doi.org/10.1016/j.chemphyslip.2017.11.017

Niehaus WG, Frielle T, Kingsley EA (1978) Purification and characterization of a secondary alcohol dehydrogenase from a pseudomonad. J Bacteriol 134(1):177-183. https://doi.org/10.1128/JB.134.1.177183.1978

Park AK, Lee GH, Kim DW, Jang EH, Kwon HT, Chi YM (2018) Crystal structure of oleate hydratase from Stenotrophomonas sp. KCTC 12332 reveals conformational plasticity surrounding the FAD binding site. Biochem Biophys Res Commun 499(4):772776. https://doi.org/10.1016/j.bbrc.2018.03.220

Radka CD, Batte JL, Frank MW, Young BM, Rock CO (2021) Structure and mechanism of Staphylococcus aureus oleate hydratase (OhyA). J Biol Chem 296:100252. https://doi.org/10.1074/jbc.RA120. 016818

Resch V, Hanefeld U (2015) The selective addition of water. Catal Sci Technol 5(3):1385-1399. https://doi.org/10.1039/C4CY00692E

Rosberg-Cody E, Liavonchanka A, Goebel C, Ross RP, O'Sullivan O, Fitzgerald GF, Feussner I, Stanton C (2011) Myosin-cross-reactive antigen (MCRA) protein from Bifidobacterium breve is a FADdependent fatty acid hydratase which has a function in stress protection. BMC Biochem 12:9. https://doi.org/10.1186/1471-2091-12-9

Salentinig S, Sagalowicz L, Glatter O (2010) Self-assembled structures and $\mathrm{pKa}$ value of oleic acid in systems of biological relevance. Langmuir 26(14):11670-11679. https://doi.org/10.1021/la101012a
Schmid J, Steiner L, Fademrecht S, Pleiss J, Otte KB, Hauer B (2016) Biocatalytic study of novel oleate hydratases. J Mol Catal B Enzym 133:S243-S249. https://doi.org/10.1016/j.molcatb.2017.01.010

Schütz R, Rawlings AV, Wandeler E, Jackson E, Trevisan S, Monneuse J-M, Bendik I, Massironi M, Imfeld D (2019) Bio-derived hydroxystearic acid ameliorates skin age spots and conspicuous pores. 41(3):240-256. https://doi.org/10.1111/ics.12529

Seo E-J, Yeon YJ, Seo J-H, Lee J-H, Boñgol JP, Oh Y, Park JM, Lim SM, Lee C-G, Park J-B (2018) Enzyme/whole-cell biotransformation of plant oils, yeast derived oils, and microalgae fatty acid methyl esters into n-nonanoic acid, 9-hydroxynonanoic acid, and 1,9nonanedioic acid. Bioresour Technol 251:288-294. https://doi.org/ 10.1016/j.biortech.2017.12.036

Seo E-J, Kang CW, Woo J-M, Jang S, Yeon YJ, Jung GY, Park J-B (2019a) Multi-level engineering of Baeyer-Villiger monooxygenase-based Escherichia coli biocatalysts for the production of C9 chemicals from oleic acid. Metabolic Engineering 54: 137-144. https://doi.org/10.1016/j.ymben.2019.03.012

Seo E-J, Kim H-J, Kim M-J, Kim J-S, Park J-B (2019b) Cofactor specificity engineering of a long-chain secondary alcohol dehydrogenase from Micrococcus luteus for redox-neutral biotransformation of fatty acids. Chem Commun 55(96):14462-14465. https://doi.org/10. 1039/C9CC06447H

Song J-W, Jeon E-Y, Song D-H, Jang H-Y, Bornscheuer UT, Oh D-K, Park J-B (2013) Multistep enzymatic synthesis of long-chain $\alpha, \omega-$ dicarboxylic and $\omega$-hydroxycarboxylic acids from renewable fatty acids and plant oils. Angew Chem Int Ed 52(9):2534-2537. https:// doi.org/10.1002/anie.201209187

Song J-W, Lee J-H, Bornscheuer UT, Park J-B (2014) Microbial synthesis of medium-chain $\alpha, \omega$-dicarboxylic acids and $\omega$ aminocarboxylic acids from renewable long-chain fatty acids. Adv Synth Catal 356(8):1782-1788. https://doi.org/10.1002/adsc. 201300784

Song J-W, Seo J-H, Oh D-K, Bornscheuer UT, Park J-B (2020) Design and engineering of whole-cell biocatalytic cascades for the valorization of fatty acids. Catal Sci Technol 10(1):46-64. https://doi.org/10. 1039/C9CY01802F

Sorigué D, Légeret B, Cuiné S, Blangy S, Moulin S, Billon E, Richaud P, Brugière S, Couté Y, Nurizzo D, Müller P, Brettel K, Pignol D, Arnoux P, Li-Beisson Y, Peltier G, Beisson F (2017) An algal photoenzyme converts fatty acids to hydrocarbons. Science 357(6354):903-907. https://doi.org/10.1126/science.aan6349

Subramanian C, Frank MW, Batte JL, Whaley SG, Rock CO (2019) Oleate hydratase from Staphylococcus aureus protects against palmitoleic acid, the major antimicrobial fatty acid produced by mammalian skin. J Biol Chem 294:9285-9294. https://doi.org/10. 1074/jbc.RA119.008439

Suga K, Kondo D, Otsuka Y, Okamoto Y, Umakoshi H (2016) Characterization of aqueous oleic acid/oleate dispersions by fluorescent probes and Raman spectroscopy. Langmuir 32(30):7606-7612. https://doi.org/10.1021/acs.langmuir.6b02257

Sun Q-F, Zheng Y-C, Chen Q, Xu J-H, Pan J (2021) Engineering of an oleate hydratase for efficient $\mathrm{C} 10$-Functionalization of oleic acid. Biochem Biophys Res Commun 537:64-70. https://doi.org/10. 1016/j.bbrc.2020.12.039

Tarola AM, Girelli AM, Lorusso S (2012) High Performance liquid chromatography determination of fatty acids in drying oils following lipase action. J Chromatogr Sci 50(4):294-300. https://doi.org/10. 1093/chromsci/bms005

Todea A, Hiseni A, Otten LG, Arends IWCE, Peter F, Boeriu CG (2015) Increase of stability of oleate hydratase by appropriate immobilization technique and conditions. J Mol Catal B Enzym 119:40-47. https://doi.org/10.1016/j.molcatb.2015.05.012

Volkov A, Liavonchanka A, Kamneva O, Fiedler T, Goebel C, Kreikemeyer B, Feussner I (2010) Myosin cross-reactive antigen of Streptococcus pyogenes M49 encodes a fatty acid double bond 
hydratase that plays a role in oleic acid detoxification and bacterial virulence. J Biol Chem 285:10353-10361. https://doi.org/10.1074/ jbc.M109.081851

Volkov A, Khoshnevis S, Neumann P, Herrfurth C, Wohlwend D, Ficner R, Feussner I (2013) Crystal structure analysis of a fatty acid doublebond hydratase from Lactobacillus acidophilus. Acta Crystallogr D 69(4):648-657. https://doi.org/10.1107/S0907444913000991

Wallen LL, Benedict RG, Jackson RW (1962) The microbiological production of 10-Hydroxystearic acid from oleic acid. Arch Biochem Biophys 99:249-253. https://doi.org/10.1016/0003-9861(62) 90006-1

Wu Y-X, Pan J, Yu H-L, Xu J-H (2019) Enzymatic synthesis of 10oxostearic acid in high space-time yield via cascade reaction of a new oleate hydratase and an alcohol dehydrogenase. J Biotechnol X 2:100008. https://doi.org/10.1016/j.btecx.2019.100008

Yang B, Chen H, Song Y, Chen YQ, Zhang H, Chen W (2013) Myosincross-reactive antigens from four different lactic acid bacteria are fatty acid hydratases. Biotechnol Lett 35(1):75-81. https://doi.org/ 10.1007/s10529-012-1044-y

Zhang W, Lee J-H, Younes SHH, Tonin F, Hagedoorn P-L, Pichler H, Baeg Y, Park J-B, Kourist R, Hollmann F (2020a) Photobiocatalytic synthesis of chiral secondary fatty alcohols from renewable unsaturated fatty acids. Nat Commun 11(1):2258. https://doi.org/10.1038/ s41467-020-16099-7

Zhang Y, Eser BE, Kristensen P, Guo Z (2020b) Fatty acid hydratase for value-added biotransformation: a review. Chin J Chem Eng 28(8): 2051-2063. https://doi.org/10.1016/j.cjche.2020.02.008

Zhang Y, Eser BE, Guo Z (2021) A bi-enzymatic cascade pathway towards optically pure FAHFAs. Chem Eur J 22(12):2146-2153. https://doi.org/10.1002/cbic.202100070

Publisher's note Springer Nature remains neutral with regard to jurisdictional claims in published maps and institutional affiliations. 